\title{
DIAGNÓSTICO DO USO DO FOGO NO ENTORNO DO PARQUE ESTADUAL DA SERRA DO BRIGADEIRO (PESB), MG $^{1}$
}

\author{
Verônica Rocha Bonfim², Guido Assunção Ribeiro ${ }^{3}$, Elias Silva ${ }^{4}$ e Geraldo Magela Braga ${ }^{5}$
}

\begin{abstract}
RESUMO - O emprego do fogo é uma prática alternativa comum no meio rural, por ser uma técnica eficiente para diversas finalidades na visão de muitos agricultores. Esta técnica requer uma série de cuidados para não incorrer em desastres ambientais, como incêndios florestais. Os objetivos deste trabalho foram realizar um diagnóstico do uso do fogo pelos produtores rurais do entorno do Parque Estadual da Serra do Brigadeiro (PESB), Estado de Minas Gerais, e verificar sua percepção com relação aos incêndios florestais. Para tanto, foram amostradas três regiões distintas e representativas do entorno do PESB: Araponga, Pedra Bonita e Fervedouro. Os dados foram obtidos mediante entrevistas semi-estruturadas, com uso de questionário. Concluiu-se que o uso do fogo é ainda uma prática comum entre os produtores rurais, por ser mais viável economicamente e pelo seu rápido efeito. Entretanto, há um consenso sobre os prejuízos que ele pode causar ao solo, às suas vidas e ao meio ambiente.
\end{abstract}

Palavras-chave: Incêndios florestais, Unidades de Conservação, uso do fogo e meio ambiente.

\section{DIAGNOSIS OF THE USE OF FIRE AT PARQUE ESTADUAL DA SERRA DO BRIGADEIRO (PESB), MG}

\begin{abstract}
The use of fire slash and Burn is a common alternative practice in the rural area, seen by many farmers as an efficient technique for various purposes. However, this technique should be carefully employed so as not to cause environmental disasters, such as forest fires. The objective of this work is to make a diagnosis of the use of fire by farmers nearby the Parque Estadual da Serra do Brigadeiro (PESB), in Minas Gerais and verify their perception of forest fire. The use of fire is still a common practice among farmers since it is economically viable and presents fast results. However, there is a consensus concerning its harmful effects on the soil, human life and the environment.
\end{abstract}

Key words: Forest fire, Conservation Units, use of fire and environmental.

\section{INTRODUÇÃO}

Desde os primórdios, o homem emprega o fogo objetivando a limpeza do terreno e o seu manejo para a pecuária e a agricultura. É fato que o uso do fogo é uma prática comum no meio rural, por ser uma técnica eficiente sob o ponto de vista dos produtores. Os agricultores utilizam a queima por considerá-la um meio prático para diversas finalidades, como limpeza do terreno para eliminar restos de cultura; aumento da disponibilidade de nutrientes no solo e, conseqüentemente, da sua capacidade produtiva; redução da incidência de pragas, de doenças, de gastos com mão-de-obra para limpeza do terreno; redução dos custos de produção; entre outras.

1 Recebido para publicação em 20.9.2001.

Aceito para publicação em 19.2.2003.

2 Mestre em Ciência Florestal, Dep. de Engenharia Florestal da Universidade Federal de Viçosa - UFV, 36570-000 Viçosa-MG, <verônica.bonfim@bol.com.br>; ${ }^{3}$ Professor Dept. de Engenharia Florestal da UFV, <garibeiro@mail.ufv.br>; ${ }^{4}$ Professor do Dep. de Engenharia Florestal da UFV, <eschami@mail.ufv.br>; 5 Professor do Dep. de Economia Rural da UFV, <gmbraga@mail.ufv.br>. 
O uso dessa técnica requer uma série de cuidados para não incorrer em desastres ambientais, como incêndios florestais. Segundo Lima (1998), o Brasil perde anualmente extensas áreas de florestas e de campos devido à ocorrência de incêndios.

De acordo com Soares (1992), as principais causas dos incêndios florestais no País são devido a: queima para limpeza, que corresponde a $63,7 \%$ da área queimada, seguida da queima criminosa ou provocada por incendiários (14,7\%); fogos de recreação ou acidental (11,6\%); diversos $(4,4 \%)$; fumantes $(2,9 \%)$; estradas de ferro $(0,5 \%)$; e queimas de origem natural ou provocadas por raios, que correspondem a apenas $0,2 \%$.

Grande parte das Unidades de Conservação (UCs) do Brasil vem sendo atingida, todos os anos, por incêndios florestais. O mesmo tem ocorrido nas UCs do Estado de Minas Gerais. Segundo Lima (2000), em 1999 o Estado teve cerca de 12.000 ha de área queimada, somente nas Unidades de Conservação, e em nível nacional, nesse mesmo ano, pelo menos 40.000 ha foram queimados. Somando-se a isso, ainda houve a liberação de 90.000 ha de área para queima controlada, e áreas significativas são atingidas anualmente pelas "queimadas" ou, queimas não-autorizadas, pelos incêndios em áreas particulares, pelos incêndios em margens de rodovias, pelas queimas em lotes urbanos, dentre outros.

O Parque Estadual da Serra do Brigadeiro (PESB) abrange oito municípios e seu entorno é habitado por pequenos produtores, que vivem basicamente da cafeicultura e da pecuária, o que leva a maioria deles a fazer uso do fogo em suas atividades agrícolas e pastoris, colocando em risco tanto a diversidade biológica do parque quanto a vida dos moradores locais.

Os incêndios florestais acarretam conseqüências desastrosas para o meio ambiente, sendo suas causas as mais variadas, ou seja, podem ser de caráter criminoso ou não.

Os incêndios florestais de caráter criminoso podem estar, muitas vezes, associados à falta de informação e de preparo quanto ao uso adequado do fogo. Trabalhos de conscientização ambiental e de racionalização do uso do fogo, em forma de queima controlada, são fundamentais para que os pequenos produtores possam conhecer e aplicar novas técnicas. Portanto, podem ser repassados conhecimentos sobre alternativas de uso do fogo, de forma que, ao fim do processo, eles estejam não só capacitados, como habilitados para o emprego correto dessas

R. Árvore, Viçosa-MG, v.27, n.1, p.87-94, 2003 técnicas e conscientes dos aspectos legais relacionados com a queima controlada.

A elaboração e a execução de programas de educação ambiental de forma participativa e preventiva constituem uma possível solução para essa problemática. Desta forma, um diagnóstico detalhado quanto ao uso do fogo no entorno dessas unidades representaria um passo inicial para execução e garantia da eficácia desses programas. Portanto, acredita-se que este estudo oferecerá subsídios a outros projetos vinculados ao PESB, como a elaboração do Plano de Manejo do Parque ao qual está vinculado o programa de proteção contra incêndios florestais.

Com base neste cenário, o presente estudo teve como objetivo realizar um diagnóstico do uso do fogo pelos produtores rurais do entorno do Parque Estadual da Serra do Brigadeiro (PESB), bem como verificar sua percepção com relação à problemática dos incêndios florestais com base neste diagnóstico.

\section{MATERIAL E MÉTODOS}

O presente estudo foi realizado no ano de 2000, no entorno do Parque Estadual da Serra do Brigadeiro (PESB), em três municípios confrontantes que possuem área dentro do parque: Fervedouro (3.525 ha), Araponga (5.420 ha) e Pedra Bonita (372 ha).

O Parque Estadual da Serra do Brigadeiro foi criado em 27 de setembro de 1996. É uma Unidade de Conservação administrada pelo Instituto Estadual de Florestas (IEF), do Estado de Minas Gerais, e possui uma área total de 13.214 ha. Por ser uma unidade criada recentemente (Decreto ${ }^{\circ}$ 38.319, de 27 de setembro de 1996), o parque ainda não possui plano de manejo.

De acordo com Rolim (1999), o Parque Estadual da Serra do Brigadeiro está situado entre os meridianos $40^{\circ} 20^{\prime}$ e $42^{\circ} 40^{\prime}$ oeste e os paralelos $20^{\circ} 33^{\prime}$ e $21^{\circ} 00^{\prime}$ sul, ocupando o extremo norte da Serra da Mantiqueira, entre os vales do Carangola, Glória e Rio Doce. É considerado uma das reservas naturais mais importantes do Estado do Minas Gerais e possui espécies raras, algumas em extinção e muitas ainda não catalogadas. Sua área é caracterizada pela Floresta Atlântica de Encosta (Floresta Estacional Semidecidual Submontana) e por Campos de Altitude.

O parque contribui para preservação de dois importantes biomas ameaçados de extinção: a Mata Atlântica 
e os Campos de Altitude. A Serra do Brigadeiro está localizada em um divisor de águas, contribuindo, significativamente, para o abastecimento das bacias do rio Doce e rio Paraíba do Sul (Rolim, 1999).

As informações necessárias para este diagnóstico foram obtidas por meio de levantamento de campo, mediante entrevistas semi-estruturadas, com uso de questionário, direcionadas aos produtores rurais.

A presente pesquisa teve caráter exploratório e dissertativo, portanto recorreu-se à Estatística Descritiva. Os dados levantados foram processados no programa SPSS (Statistical Package for the Social Sciences), que possibilita trabalhar com distribuições de freqüências, tabulações cruzadas médias, correlações, regressão múltipla, análise fatorial e outras técnicas estatísticas (Gil, 1999). Com este programa foram obtidas a distribuição de freqüências, considerada por Botelho \& Maciel (1983) a série estatística mais importante dentro da estatística descritiva, e a média aritmética, medida de posição que possibilita condensar as informações obtidas pelos dados.

O presente estudo está enquadrado dentro da pesquisa por amostragem, cujo objetivo, de acordo com Flores Junior (1980), não é descrever os indivíduos particulares que por acaso tenham sido contemplados na amostra, e sim obter um perfil estatístico da população estudada.

As freqüências obtidas nos resultados são referentes às variáveis do questionário, e não referentes aos entrevistados, não possuindo, portanto, efeito cumulativo. Cada entrevistado pode ou não ter respondido a uma ou mais variáveis, conseqüentemente algumas freqüências podem ter resultado em valores acima de $100 \%$.

\section{RESULTADOS E DISCUSSÃO}

Com este estudo foi possível observar e analisar os aspectos histórico-econômicos em que o uso do fogo está inserido. Para tal, foi realizado um levantamento de campo que resultou em 94 questionários, ou seja, foram obtidas informações de 94 produtores rurais existentes nas três localidades descritas na área de estudo da presente pesquisa. No Quadro 1, podem ser observados a localidade e o número de produtores entrevistados por região.

O maior número de entrevistados foi em Araponga, por ser este o município de maior porte e maior população. $\mathrm{O}$ menor número de entrevistados foi em Bom Jesus do Madeira, no entanto nesta localidade o número total de famílias que residem nos limites do parque corresponde a 25 , ou seja, o diagnóstico teve uma abrangência bastante satisfatória, devido ao pequeno porte do município.

Com relação ao uso do fogo, a maior parte dos entrevistados afirmou ter sido este comum há muitos anos e que hoje não é mais, segundo eles devido a motivos como: criação do parque, não ter mais o que queimar, já que "é tudo lavoura", e por serem conscientes de que, para a realidade deles, o fogo mais prejudica do que beneficia. No Quadro 2 seguem as variáveis do uso do fogo e suas respectivas características e freqüências.

Segundo os entrevistados, o uso do fogo na região é mais comum em meados de junho até outubro (Quadro 2).

O uso do fogo para fins agrícolas $(69,1 \%)$, como limpeza do terreno para implantação de culturas, é a principal finalidade para o emprego desta técnica na região, seguida da prática do fogo criminoso $(14,9 \%)$, fins agropastoris $(7,4 \%)$, não responderam $(5,3 \%)$, não souberam responder $(4,3 \%)$ e fins pastoris $(1,1 \%)$ (Quadro 2$)$.

As principais causas de incêndios na região foram as queimadas, com $50,0 \%$ das ocorrências, enquanto os incêndios provenientes de causas naturais tiveram a menor porcentagem, com apenas $2,1 \%$ das ocorrências, como apresentado no Quadro 3.

Entre as principais causas dos incêndios na região, a queimada obteve maior freqüência $(50,0 \%)$, seguida de causas criminosas $(23,4 \%)$, causas desconhecidas $(36,1 \%)$, causa acidental $(3,2 \%)$ e causa de origem natural $(2,1)$.

No Quadro 4, pode ser observado que a maior parte dos produtores nega a fazer uso do fogo. Dentre os entrevistados que usam ou já fizeram uso do fogo, a maior freqüência foi para fins agrícolas, seguido de fins pastoris e fins agropastoris.

Alguns entrevistados que fazem ou já fizeram uso do fogo afirmaram que já aconteceu de não conseguir controlá-lo e que a maior parte dos produtores recorre aos vizinhos ou companheiros para auxiliar no combate, outros deixavam-no apagar sozinho e houve quem argumentou não existir, na época, o Instituto Estadual de Florestas - IEF, que deveria fazer a fiscalização.

Com relação ao uso de medidas de preventivas, o aceiro foi a mais comum, com aproximadamente $96 \%$ de freqüência. Este dado revela a falta de conhecimento

R. Árvore, Viçosa-MG, v.27, n.1, p.87-94, 2003 
Quadro 1 - Localidade e município correspondente, freqüência absoluta e relativa de entrevistados por região na área de estudo

Table 1 - Place and absolute and relative frequencies of farmers interviewed by region

\begin{tabular}{|c|c|c|}
\hline Localidade/Município & Freqüência Absoluta & Freqüência Relativa (\%) \\
\hline Bom Jesus do Madeira/Fervedouro & 21 & 22,3 \\
Estouro/Araponga & 44 & 46,8 \\
Matipó/Pedra Bonita & 29 & 30,9 \\
\hline Total & 94 & 100,0 \\
\hline
\end{tabular}

ou descaso quanto ao uso de critérios e medidas preventivas que antecedem uma queima. Os critérios mencionados pelos entrevistados foram: observar as condições do vento; observar a hora do dia e usar técnicas de queima controlada conforme o local; fazer vigília; esperar a época propícia; fazer coivara; avisar o IEF antes de proceder à queima; avisar os vizinhos; e limpar periodicamente, para retirada de material combustível (Quadro 4). Portanto conclui-se que as medidas de prevenção estão sendo aplicadas, porém de forma fragmentada, não surtindo o devido efeito.

O uso do fogo, quando são observadas todas as medidas preventivas que prescreve uma queima controlada, pode ser uma ferramenta útil ao homem no meio rural. Entretanto, é sabido que seus efeitos são drásticos a médio e longo prazo. Nessa região do entorno do PESB, segundo o Centro de Tecnologias Alternativas da Zona da Mata-CTA/ZM (1999), o principal problema identificado nos sistemas de produção foi o esgotamento, em locais onde o fogo é constantemente utilizado, dos selos utilizados intensivamente para produção de café, consorciado com milho e, ou, feijão e arroz-de-sequeiro. Com o esgotamento dos solos, as áreas de cultura são transformadas em pastagens de baixa produtividade. Todos produtores entrevistados concordam que o fogo provoca efeitos danosos, como desgastes físico e químico no solo, pois eles estão percebendo e vivenciando as conseqüências no seu dia-a-dia.

No Quadro 5 estão as variáveis relacionadas aos principais problemas causados pelo fogo e alternativas ao uso do fogo mencionados na pesquisa.

Entre os problemas que o fogo pode causar, observou-se que os de cunho ambiental prevaleceram sobre os demais. Os entrevistados deram ênfase à questão do solo e da água, com frases do tipo: "acaba com o esterco da terra", "seca as nascentes", e "acaba com a água"; aos problemas como incêndios e mortes, considerados aqui

R. Árvore, Viçosa-MG, v.27, n.1, p.87-94, 2003
Quadro 2 - Variáveis, características e freqüência relacionadas ao uso do fogo

Table 2 - Variables, characteristics and frequencies associated to use of fire

\begin{tabular}{|l|l|c|}
\hline \multicolumn{1}{|c|}{ Variável } & \multicolumn{1}{|c|}{ Característica } & $\begin{array}{c}\text { Freqüência } \\
\text { (\%) }\end{array}$ \\
\hline Uso do fogo na & É comum & 22,3 \\
região & Não é comum & 29,8 \\
& Já foi comum há algum tempo & 47,9 \\
\hline \multirow{3}{*}{ Período de uso do } & Seca (junho a outubro) & 86,2 \\
fogo & Não responderam & 7,4 \\
& Outro período & 3,2 \\
& Não souberam responder & 3,2 \\
\hline \multirow{3}{*}{ Finalidades do uso } & Agrícola & 69,1 \\
do fogo & Criminosa & 14,9 \\
& Agropastoris & 7,4 \\
& Não responderam & 5,3 \\
& Não souberam responder & 4,3 \\
& Pastoris & 1,1 \\
\hline
\end{tabular}

Quadro 3 - Variável e sua respectiva freqüências em relação à causa dos incêndios na região

Table 3 -Variables and their frequencies related to causes of forest fires in the region

\begin{tabular}{|l|c|}
\hline \multicolumn{1}{|c|}{ Variável } & Freqüência (\%) \\
\hline Queimada & 50,0 \\
Criminosa & 23,4 \\
Não souberam responder & 19,1 \\
Não responderam & 17,0 \\
Acidental & 3,2 \\
Origem natural & 2,1 \\
\hline
\end{tabular}

como desastres de proporções irreversíveis; aos problemas de ordem econômica, como a destruição das lavouras; aos problemas de ordem social, por acreditarem que o fogo pode atingir outras áreas além dos limites da propriedade; e houve aqueles que não souberam responder. 
Constatou-se que praticamente todos os produtores têm conhecimento quanto às épocas críticas de incêndio, e estas coincidem com o período de seca, que é justamente a época que antecede o plantio, sendo o fogo utilizado no preparo da terra.

A região do entorno do PESB é caracterizada por extensas áreas de pastagens, restando poucas áreas verdes. Segundo os produtores, não existe mais o que queimar. Todavia, ainda restam fragmentos isolados de florestas e toda a área do PESB para serem protegidos. No entanto, observou-se a existência ou o conhecimento, por parte dos produtores, de formas alternativas para substituir o uso do fogo.

A grande maioria afirmou conhecer alternativas para não fazer uso do fogo $(90,4 \%)$, enquanto uma pequena parte de produtores $(9,6 \%)$ respondeu que só conhece esta prática. Entre os que afirmaram conhecer alguma prática, mereceu destaque a capina manual $(48,9 \%)$, enleirandose os restos vegetais e deixando-os apodrecer para "dar esterco, que é matéria orgânica, alimento para a terra", pois foi a prática mais comum, seguida de: capina manual apenas; algum tipo de produto químico, como adubo e calcário, "para melhorar o solo" ou como "remédio para matar o capim"; capina, limpeza e fogo, em último caso, para "deter o mato alto e samambaia"; bater pasto com foice; maquinário (trator); e animais para pisoteio e manutenção (Quadro 5).

O aviso de queima é um formulário, obtido no IEF, que o produtor deve preencher para que seja encaminhado formalmente o pedido de queima, a fim de que possa ser emitida ou não a licença, conforme cada caso particular. Com relação a este quesito, observou-se que apenas $20,2 \%$ dos entrevistados conhecem o aviso, enquanto os restantes $79,8 \%$ o desconhecem.

Geralmente, a maior parte dos produtores $(92,6 \%)$, já presenciou algum tipo de incêndio de grandes proporções, enquanto 7,4\% afirmaram nunca ter visto.

Com o intuito de perceber algum tipo de experiência ou contato direto desses produtores com um incêndio, procurou-se saber quantos deles haviam ajudado a apagar fogo pelo menos uma vez. Observou-se que muitos já haviam passado por essa experiência $(69,1 \%)$, enquanto $30,9 \%$ nunca apagaram fogo em campo (Quadro 6).

No Quadro 6 estão as experiências em combate aos incêndios florestais, bem como técnicas de combate aos incêndios florestais utilizadas pelos agricultores e suas maiores dificuldades.

Quadro 4 - Variáveis, características e freqüências em relação ao uso do fogo, à finalidade e ao controle do fogo pelos produtores e medidas preventivas

Table 4 -Variables, characteristics and frequencies associated to the use, purpose and control of fire by farmers, as well as preventive measures

\begin{tabular}{|l|l|r|}
\hline \multicolumn{1}{|c|}{ Variável } & \multicolumn{1}{c|}{ Característica } & Freqüência (\%) \\
\hline \multirow{3}{*}{ Uso do fogo pelos produtores } & Não usa fogo & 75,5 \\
& Usa fogo & 14,9 \\
& Já usou há algum tempo & 9,6 \\
\hline \multirow{3}{*}{ Finalidade e controle (para os que usam ou } & Fins agrícolas & 18,1 \\
usaram) & Fins agropastoris & 4,3 \\
& Fins pastoris & 2,1 \\
& Não conseguiu controlar pelo menos uma vez & 9,6 \\
\hline & Aceiro & 95,7 \\
& Observar as condições do vento & 38,3 \\
& Observar a hora do dia e técnicas de queima controlada & 20,2 \\
Medidas preventivas & Vigília & 10,6 \\
& Esperar época propícia & 9,6 \\
& Coivara & 6,4 \\
& Avisar o IEF & 4,3 \\
& Avisar os vizinhos & 1,1 \\
& Limpeza periódica & 1,1 \\
& Não responderam & 3,2 \\
& Não souberam responder & 1,1 \\
\hline
\end{tabular}


Quadro 5 - Variáveis, características e freqüências em relação aos principais problemas causados pelo fogo e alternativas para substituir o seu uso

Table 5 - Variables, characteristics and frequencies related to the main problems caused by fire and possible alternatives for its use

\begin{tabular}{|l|l|r|}
\hline \multicolumn{1}{|c|}{ Variável } & \multicolumn{1}{|c|}{ Característica } & Freqüência (\%) \\
\hline \multirow{4}{*}{ Principais problemas } & Ambiental & 91,5 \\
& Desastres de proporções irreversíveis & 10,6 \\
& Econômico & 6,4 \\
& Social & 4,3 \\
& Não souberam responder & 1,0 \\
\hline \multirow{2}{*}{ Alternativas } & Conhecem pelo menos uma alternativa & 90,4 \\
& Só conhecem o fogo & 9,6 \\
\hline \multirow{5}{*}{ Tipos de alternativas } & Capina manual, deixando os restos incorporarem ao solo & 48,9 \\
& Capina manual & 24,5 \\
& Química & 17,0 \\
& Capina manual, limpeza e fogo, em último caso & 11,7 \\
& Bater pasto com foice & 8,5 \\
& Maquinário & 6,5 \\
& Animais & 1,1 \\
\hline
\end{tabular}

Quadro 6 - Variáveis, características e freqüências em relação à experiência com incêndios florestais, às técnicas de combate ao fogo e às maiores dificuldades durante o combate

Table 6 -Variables, characteristics and frequencies related to forest fire experience, fire fighting techniques and greatest difficulties found in fire fighting

\begin{tabular}{|l|l|r|}
\hline \multicolumn{1}{|c|}{ Variável } & \multicolumn{1}{|c|}{ Característica } & Freqüência (\%) \\
\hline \multirow{2}{*}{ Experiência em combate ao fogo } & Já ajudou a apagar incêndio pelo menos uma vez & 69,1 \\
& Nunca apagou fogo & 30,9 \\
\hline & Aceiro & 69,1 \\
& Ramo ou Enxada & 45,7 \\
& Água & 10,6 \\
& Terra & 8,5 \\
& Helicóptero & 7,4 \\
& Equipamentos (bomba costal, abafador) & 4,3 \\
& Contra-fogo & 4,3 \\
\hline \multirow{5}{*}{ Dificuldades } & Risco de vida & 43,6 \\
& Fumaça & 28,7 \\
& Difícil acesso & 22,3 \\
& Calor & 20,2 \\
& Falta de equipamento & 7,4 \\
& Sêde & 6,4 \\
& Fogo subterrâneo & 2,1 \\
& Tudo & 1,1 \\
& Não responderam & 1,1 \\
\hline
\end{tabular}

$\mathrm{O}$ aceiro foi a medida de combate que obteve maior freqüência $(69,1 \%)$, seguido da utilização de objetos rústicos, como ramo e enxada (45,7\%); de água (10,6\%), devido ao acesso sempre difícil e à característica bastante montanhosa da região; de terra $(8,5 \%)$; de experiência como membro da brigada do IEF, mencionando o uso de

R. Árvore, Viçosa-MG, v.27, n.1, p.87-94, 2003 
helicópteros para transporte de água e pessoal (7,4\%); de equipamentos exclusivos para combate, como bomba costal e abafador (4,3\%); de técnicas de contra-fogo para apagar incêndios (4,3\%) (Quadro 6). Estes dados revelam o baixo grau de conhecimento sobre equipamentos básicos, como abafador e bomba antiincêndio.

O uso do helicóptero foi provavelmente mencionado por causa do incêndio ocorrido no parque no ano anterior ao da presente pesquisa, quando a aeronave foi utilizada para transporte de pessoal durante o combate.

Constatou-se que as maiores dificuldades encontradas para combater um incêndio foram as características montanhosa e pedregosa da região, visto que o risco de vida, com relação a cobra, queimaduras, pedras rolando, locais com alto grau de periculosidade devido a declividade e acidentes fatais, foi o mais citado pelos entrevistados. O segundo grupo de dificuldade mencionado pelos entrevistados que já tiveram alguma experiência no combate aos incêndios foi a presença de fumaça, o acesso difícil e a exposição ao calor. Portanto, concluise que tais brigadistas não usavam equipamentos de proteção individual (E.P.I.) durante o combate, como máscara e roupas apropriadas, embora não tenham feito referência (Quadro 6).

Aproximadamente $14,0 \%$ dos entrevistados mencionaram três pontos fundamentais: falta de equipamento e de pessoal e sede, apontados como negativos em suas experiências de combate ao fogo, revelando falta de apoio logístico e de condições adequadas de trabalho, o que coloca em risco a segurança dos brigadistas (Quadro 6).

As demais dificuldades levantadas pelos entrevistados, com cerca de $4,3 \%$, são mais generalistas e traduzem um certo temor e desconhecimento a respeito do fogo como incêndio florestal, pois, devido ao acesso, a obtenção de água muitas vezes é impossível, há ocorrência de fogo subterrâneo, tudo é difícil e outros não responderam (Quadro 6).

\section{CONCLUSÕES}

Pelos resultados obtidos com o diagnóstico, podese concluir que:

a) O uso do fogo no entorno do Parque Estadual da Serra do Brigadeiro (PESB) possui finalidades agropastoris, sendo ainda uma realidade para os produtores do entorno, principalmente entre os meses de junho a outubro, quando ocorre o período de seca na região. b) Existe um consenso sobre os prejuízos que o fogo pode causar ao solo, à vida do ser humano e ao meio ambiente. A principal preocupação é em termos ambientais, tendo em vista que a redução do número de nascentes na região e o esgotamento do solo são fatores reais e percebidos pelas comunidades locais.

c) Em geral, os produtores não possuem conhecimento, nem conscientização, sobre a legislação que rege o uso do fogo. Desconhecem o aviso de queima, mas têm consciência de que precisam retirar licença para queima, entretanto, em sua grande maioria, não o fazem, seja por descaso, seja pelo excesso de burocracia existente nos órgãos públicos.

d) As populações locais confessam conhecer técnicas alternativas para substituir o uso do fogo, como a capina manual, deixando os resíduos incorporarem ao solo, o que contribui para redução das enxurradas e aumento da matéria orgânica. Entretanto, devido à falta de apoio com maquinário, os gastos reduzidos com mão-de-obra e o imediatismo tão presente no homem contemporâneo fazem com que o emprego do fogo no meio rural seja a técnica mais recorrida.

e) Os produtores rurais do entorno, de modo geral, utilizam o aceiro para realização da queima controlada, mas este, muitas vezes, é feito meses antes da queima, tornando-se ineficiente por estar praticamente tomado novamente por material combustível. Além disto, muitos não obedecem às dimensões apropriadas dos aceiros para a área a ser queimada.

f) As técnicas de segurança pessoal não fazem parte da realidade dos produtores.

g) A principal causa dos incêndios na região foram as queimadas para fins agropastoris, não diferenciando das estatísticas nacionais de incêndios em Unidades de Conservação.

h) A percepção ambiental com relação aos incêndios florestais e seus efeitos sobre o meio ambiente, verificada através deste diagnóstico, é algo que ainda precisa ser trabalhado entre os produtores rurais do entorno do PESB, em associação com trabalhos de educação ambiental.

\section{REFERÊNCIAS BIBLIOGRÁFICAS}

BOTELHO, E. M. D.; MACIEL, A. J. Estatística descritiva, Viçosa, MG: UFV, 1983. 65 p.

R. Árvore, Viçosa-MG, v.27, n.1, p.87-94, 2003 
CENTRO DE TECNOLOGIAS ALTERNATIVAS DA ZONA DA MATA - CTA/ZM. Aspectos sócio-econômicos, relação com o entorno e educação ambiental. In: SIMPÓSIO PARQUE ESTADUAL DA SERRA DO BRIGADEIRO E ENTORNO: CONTRIBUIÇÕES PARA ELABORAÇÃO DO PLANO DE MANEJO INTEGRADO E PARTICIPATIVO, 1., 1999, Viçosa, MG. Simpósio... Viçosa, MG: IEF/UFV, 1999. 6 p. (Apostila distribuída durante palestra)

FLORES JUNIOR, R. G. O que é uma pesquisa por amostragem? Rio de Janeiro: IBGE [1980]. 47 p.

GIL, A. C. Métodos e técnicas de pesquisa social. 5.ed. São Paulo: ATLAS, 1999. 206 p.
LIMA, G. S. A educação ambiental na prevenção de incêndios florestais. In: SEMINÁRIO SUL-AMERICANO SOBRE CONTROLE DE INCÊNDIOS FLORESTAIS, 1., 1998, Belo Horizonte. Anais... Viçosa, MG: SIF/UFV, 1998. p. 46-57.

LIMA, G. S. Os incêndios florestais no Estado de Minas Gerais. Revista Ação Ambiental, v. 2, n. 12, p. 15-18, 2000.

ROLIM, F. A. Levantamento do potencial turístico do Parque Estadual da Serra do Brigadeiro. Viçosa, MG: UFV, 1999. 61 p. (Monografia de conclusão de curso)

SOARES, R.V. Ocorrência de incêndios em povoamentos florestais. Revista Floresta, v. 22, n. 1-2, p.39-54, 1992. 